\title{
Influence of lifestyle factors on long-term sickness absence among female healthcare workers: a prospective cohort study
}

Helle Gram Quist ${ }^{1 *}$, Birthe L Thomsen 1, Ulla Christensen², Thomas Clausen', Andreas Holtermann1, Jakob B Bjorner ${ }^{1,2,3}$ and Lars L Andersen ${ }^{1}$

\begin{abstract}
Background: While previous research has indicated that unhealthy lifestyle is associated with sickness absence, this association may be confounded by occupational class. To avoid this potential confounding, we examined the association between lifestyle factors (smoking, leisure-time physical activity and body mass index) and the occurrence of long-term sickness absence (LTSA; more than three consecutive weeks of registered sickness absence) within a cohort of female health care workers.

Methods: A total of 7401 employees filled out a questionnaire about their health behaviour and work environment. Subsequently, they were followed for 12 months in a national register on social transfer payments (DREAM register). Cox's regression analyses, applied to grouped survival data, were used to estimate the prospective association between these lifestyle factors and LTSA.

Results: We found significant associations between all three lifestyle factors and risk of LTSA. The strongest lifestyle factor was current smoking, which increased the risk of LTSA by $35 \%$ (95\% Cl: 1.17-1.54) compared to non- smokers. For body mass index, the risk of LTSA increased with the distance away from $18.5 \mathrm{~kg} / \mathrm{m}^{2}$ in either direction (below $18.5 \mathrm{~kg} / \mathrm{m}^{2}$ : HR: 1.32 per kg/m²; 95\% Cl. 1.06-1.66; above $18.5 \mathrm{~kg} / \mathrm{m}^{2}$ : HR: 1.04 per kg/m²; 95\% Cl: 1.03-1.05). In other words, the more underweight or overweight the women were, the higher the risk of LTSA. A dose-response relationship was found between LTSA and leisure-time physical activity (trend test p-value $=0.01$ ), so that increasing physical activity results in decreasing risk of LTSA.
\end{abstract}

Conclusion: In female healthcare workers, an unhealthy lifestyle (too high/ too low body mass index, smoking, and low physical activity) is associated with higher risk of LTSA.

Keywords: Long-term sickness absence, Lifestyle, Smoking, Body mass index, Physical activity, Cohort study

\section{Background}

Sickness absence, and in particular, the reduction of sickness absence, has been on the political agenda in Denmark for years. The healthcare sector ranks particular high in sickness absenteeism [1]. To reduce the costs of sickness absence for the society, regulations on sick leave have become more restricted in the past years [2]. Further, worksites have increased their focus on general well-being and health promotion for the employees in

\footnotetext{
* Correspondence: hgq@nrcwe.dk

'National Research Centre for the Working Environment, Lerso Parkallé 105, 2100 Copenhagen, Denmark

Full list of author information is available at the end of the article
}

an attempt to reduce sickness absence and improve work attendance. Sickness absence express a complex relationship between health and work characteristics [3] and is caused by a variety of factors, including occupational injuries and work related factors, such as physical demands, perceived exertion and psychosocial exposures [4-7]. However, research also indicates that sickness absence, and affiliation with the labour market in general, are influenced by personal health behaviours $[4,6,8-10]$. Sickness absence can be seen as an early indicator of illness and has been suggested as a measure of health and functioning in working populations [11]. A Danish research study has found that the longer duration of sickness absence 
the higher the risk of future disability pension, indicating that long-term sickness absence (LTSA) is also a predictor of expulsion from the labour marked [12].

Previous research has found associations between sickness absence and smoking [8,13-15], obesity [13-15] and leisure-time physical activity [16-18]. In general, it has been found that smoking, lack of moderate and/or vigorous leisure-time physical activity, and obesity increases the risk of sickness absence. Also, a study on the association between body mass index (BMI) and mortality found that the strongest association was for those with low BMI [19]. Together, this could potentially indicate a v-shaped relationship between BMI and LTSA as well. However, studies on the association between underweight and sickness absence are rather uncommon in the literature and the results are inconsistent [20].

It is well documented that there exist a social gradient in lifestyle. Unhealthy lifestyles, such as smoking, lack of physical activity, and poor dietary habits are associated with socioeconomic status (e.g. educational level, affiliation with the labour market and income) [21,22]. Individuals with short educational background, and those standing outside the labour market, generally have more unfavourable lifestyles than those with a longer education [22]. Other significant predictors of sickness absence are occupational class and working conditions $[9,10,15,23,24]$. These may therefore be potential confounders in the association between lifestyle and sickness absence. As differences exist among different occupational groups, it is important to control for social class - e.g. by stratification or restriction of the sample. Therefore, we have studied the association between lifestyle and sickness absence in a homogenous group of health care workers. Previously mentioned studies $[8,13,14,16-18]$ controlled for social class either by socioeconomic position, occupational class or by restriction of the sample. The approach of examining the association among health care workers only, helps us circumvent the issue of confounding by social class to a large extent. Furthermore, research indicates that women have higher rates of sickness absence than men [25]. The work environment also seem to have different effects of sickness absence for men and women [26,27]. This study is limited to women.

The aim of this study was to investigate the prospective association between lifestyle factors (smoking, BMI and leisure-time physical activity) and the risk of LTSA in a female cohort of health care workers, with and without adjustment for work related factors.

\section{Methods}

The present study is based on survey data collected by postal questionnaires among female employees in the eldercare sector in Denmark. Data on long-term sickness absence was obtained by linkage to the Danish
Register for Evaluation of Marginalization (DREAM), which is a register on social transfer payments [28]. The survey was conducted in the fall of 2004 and spring of 2005 and aimed at examining the health and working conditions of health care workers. Of the 65 municipalities invited to participate, 36 enrolled in the study. A total of 9,949 employees ( $78 \%$ of the total 12,746 employees) chose to participate. Analyses indicated that the participation rate was lowest among men, younger employees, and among service personnel [29]. There was a slight overrepresentation of small municipalities in the study, and although the participating municipalities were not representative in terms of geographically location, they were representative in terms of demographics, the labour market, service-level within the healthcare area and socioeconomic wealth in the municipality.

We excluded men $(n=429)$ and employees in management or service production (e.g. kitchen staff, janitors, secretaries etc.; $n=1586$ ) from the analyses. It was required that all respondents were healthy (not receiving sickness benefits) at baseline and were associated with the work force. Thus, we excluded a total of 419 respondents with current sickness absence at baseline and 114 for having an uncertain affiliation with the work force at baseline (e.g. unemployment, maternity leave, starting allowance, or rehabilitation benefits).

As a result, the target population consisted of 7401 female employees in health-related care services functions (2548 respondents were excluded in total). Due to the exclusion of men and those in management and service functions, the lower response rate among these employees is not considered an issue for the analyses pertaining to this study. The respondents were subsequently identified in the DREAM register and followed for one year after completion of the questionnaire. The study has been approved by the Danish Data Protection Agency. According to Danish law, questionnaire research does not require approval by ethic committees or informed consent.

\section{Outcome variable: long-term sickness absence}

We wanted to study LTSA using an objective register based measurement to avoid response bias on the outcome. In Denmark, all social benefits, including sickness absence benefits, are registered in the DREAM register [28]. LTSA from the DREAM register [28] was linked to survey data via the unique Danish personal identification number, which is a ten-digit number given to all Danish citizens at birth. The DREAM register contains weekly information about all public transfer payments and includes everyone who has received social benefits or other types of transfer income since 1991. Sickness absence compensation is given to the employer by applying for a refund from the government. At the time of the study such a refund was generally given after 13 calendar days of sickness absence 
(though some employers are entitled to a refund from the beginning of the sick leave). The employer is required to pay for the initial period, which is referred to as the "employer period". As sickness absence is registered per whole week in DREAM (and not by single days), it was necessary to choose three weeks of registred absence as cut-point in order to reflect the employer period. The validity of the sickness absence data in DREAM is considered high [30,31].

\section{Lifestyle factors}

Three lifestyle factors were assessed in this study: smoking, BMI and leisure-time physical activity. Smoking was categorized into current smoker, former smoker, and never smoker. Never smokers served as the reference group. BMI was calculated based on the respondents' self-reported information on height and weight $\left(B M I=\mathrm{kg} / \mathrm{m}^{2}\right)$. Leisuretime physical activity was assessed with a single question: "Which description most precisely covers your pattern of physical activity at leisure time during the last 12 months?" Four response categories (ranging from low to high duration and intensity) were utilized: (i) Mainly sedentary or light physical activity for less than 2 hours per week (e.g. you read, watch television, go to the cinema); (ii) Light physical activity for 2-4 hours per week (e.g. you go for a walk, light gardening, light physical exercise); (iii) Light physical activity for more than 4 hours per week or vigorous physical exercise for 2-4 hours per week (e.g. fast jogging or cycling, heavy gardening, exercise where you are sweating and breathing heavily); (iv); Vigorous physical exercise for more than 4 hours per week or taking part in regular competitive sports several times a week [1,32]. In the tables, these are referred to as sedentary, light, moderate (reference group) and vigorous leisure-time physical activity. Moderately active respondents were presented as the reference group as they constituted the largest group (49\%).

\section{Confounders}

The potential confounders in this study included age, tenure (years working as health care worker), occupational type, physical workload and four indicators of psychosocial work conditions and previous LTSA. The assessment of physical workload was based on the Hollmann Index questionnaire asking about body postures and weight lifted during the workday (scale 0-62; 62 represents the highest degree of physical demands) [33]. The psychosocial work environment was assessed with four dimensions from the Copenhagen Psychosocial Questionnaire (COPSOQ): (i) emotional demands (3 items, e.g. "Do you get emotionally involved in your work"), (ii) role conflicts (4 items, e.g. "Are contradictory demands placed at your work"), (iii) influence at work (4 items, e.g. "Do you have a say in choosing who you work with") and (iiii) quality of leadership (4 items, e.g. "To what extent would you say that your immediate superior is good at solving conflicts") $[34,35]$. These particular psychosocial work factors have previously been found to be significantly associated with lifestyle [36,37] and with the risk of LTSA among nurses within the Danish eldercare services [24]. The psychosocial factors were included separately in the model. Previous LTSA (within one year prior to completing the questionnaire) was included as a confounder in Model 4.

\section{Statistical analyses}

To analyse whether, and to what extent, lifestyle risk factors predicted the onset of LTSA during the first year of follow up, we used Cox's proportional hazards model applied to grouped survival data [38]. We used calendar time as the time scale, with delayed entry at the time of responding to the questionnaire. Hazard ratios (HR) and 95\% confidence intervals (95\% CI) were calculated for each lifestyle risk factor.

Smoking status and leisure-time physical activity were assessed as categorical variables, while

BMI and all quantitative confounders were modelled as linear splines. We used linear splines to model the association between the variables and LTSA since using this flexible model avoids unnecessary categorization while not assuming a simple linear relationship [39]. A single knot for BMI was chosen at $18.5 \mathrm{~kg} / \mathrm{m}^{2}$, which corresponds to the beginning of being normal weight of the standardized BMI categories. The adequacy of having only one knot at $18.5 \mathrm{~kg} / \mathrm{m}^{2}$ was evaluated in a model using linear splines with knots according to the standard categorization of BMI $\left(18.5,25\right.$, and $\left.30 \mathrm{~kg} / \mathrm{m}^{2}\right)$. For all models presented in this paper, additional knots at 25 and $30 \mathrm{~kg} / \mathrm{m}^{2}$ gave no significant improvement (all p-values $>0.93$ ).

Knots for age were chosen at five-year intervals $(25,30,35,40,45,50,55,60$ years of age), while knots for tenure were chosen at five and ten years of work experience ( $<5$ years, between five and ten years, $>10$ years). The remaining confounders had the knots chosen so that approximately one-third of the women with incident LTSA were included in each interval.

In Model 1 we assessed the separate effect of each lifestyle factors on LTSA while adjusting for age. In our main model (Model 2), we examined the effects of the combined lifestyle risk factors while adjusting for age. In Model 3, we additionally adjusted for the following work-related factors: tenure, occupational type (care helper, care assistant, registered nurse etc.), physical work demands and psychosocial work dimensions. In the final model (Model 4), we also adjusted for previous long-term sickness absence (in the year prior to completion of the questionnaire).

Time since completion of the questionnaire was not included in the model, since filling out the questionnaire is unlikely to affect the incidence rate of LTSA. Each 
respondent was included in the analyses from completion of the questionnaire and until the occurrence of LTSA, retirement, death, emigration, or end of 12 month follow-up - whichever came first. The estimation method was maximum likelihood and the statistical analyses were performed with the SAS Proc Genmod procedure, version 9.2 (SAS Institute).

\section{Results}

Baseline characteristics of the female health-care workers are presented in Table 1.

A total of 1198 people (16.2\%) experienced LTSA within one year after completing the questionnaire. On average

Table 1 Descriptive statistics of the population

\begin{tabular}{cccc}
\hline & \multicolumn{3}{c}{ Long-term Sickness } \\
\cline { 2 - 3 } Variable & $\mathrm{N}$ & $\begin{array}{c}\text { Mean }(2.5-97.5 \\
\text { percentile })\end{array}$ & $\begin{array}{c}\text { Event } \\
(\%)\end{array}$ \\
\hline
\end{tabular}

Baseline $2005(n=7401)$

$\begin{array}{lcc}\text { Age } & 7401 & 45.2(24-60) \\ \text { Seniority (years working } & 7306 & 9.0(1-28)\end{array}$

as health care worker) ${ }^{\text {a }}$

Occupational type:

\begin{tabular}{|c|c|c|c|}
\hline Care helpers & 4595 & & $824(11.2)$ \\
\hline Care assistants & 1304 & & $198(2.7)$ \\
\hline Unskilled care helpers & 162 & & $24(0.3)$ \\
\hline Registered nurses & 936 & & $106(1.4)$ \\
\hline Therapists and activity workers & 404 & & $46(0.6)$ \\
\hline \multicolumn{4}{|l|}{ Physical activity ${ }^{\mathrm{b}}$ : } \\
\hline Sedentary & 305 & & $60(19.7)$ \\
\hline Light activity & 3028 & & $518(17.2)$ \\
\hline Moderate activity & 3604 & & $555(15.4)$ \\
\hline Hard activity & 341 & & $40(11.8)$ \\
\hline \multicolumn{4}{|l|}{ Smoking status ${ }^{c}$ : } \\
\hline Never smoker & 2817 & & $395(14.1)$ \\
\hline Ex-smoker & 1778 & & $274(15.5)$ \\
\hline Current smoker & 2724 & & $511(18.8)$ \\
\hline BMI $\left(\mathrm{kg} / \mathrm{m}^{2}\right)^{\mathrm{d}}$ & 7066 & $24.9(18.7-35.6)$ & \\
\hline \multicolumn{4}{|l|}{ BMI category ${ }^{d}$ : } \\
\hline Underweight $\left(<18.5 \mathrm{~kg} / \mathrm{m}^{2}\right)$ & 140 & & $21(15.1)$ \\
\hline Normal weight $\left(18.5-24.9 \mathrm{~kg} / \mathrm{m}^{2}\right)$ & 4021 & & $573(14.3)$ \\
\hline Overweight $\left(25-29.9 \mathrm{~kg} / \mathrm{m}^{2}\right)$ & 2059 & & $357(17.4)$ \\
\hline Obese $\left(>30 \mathrm{~kg} / \mathrm{m}^{2}\right)$ & 846 & & $184(21.9)$ \\
\hline \multicolumn{4}{|l|}{$\begin{array}{l}\text { Previous long-term } \\
\text { sickness absence: }\end{array}$} \\
\hline Yes & 1045 & & $293(28.1)$ \\
\hline No & 6356 & & $905(14.3)$ \\
\hline
\end{tabular}

${ }^{\mathrm{a}} 95$ missing responses.

${ }^{\mathrm{b}} 123$ missing responses.

' 82 missing responses.

$d_{335}$ missing responses. the respondents were 45.2 years old and had worked as health care workers for 9 years. Approximately 82\% were care helpers and assistants, while almost $13 \%$ were registered nurses and $2 \%$ were therapists. On average the respondents had a BMI of 24.9 and approximately every other person (46\%) indicated that they had a light or sedentary leisure-time physical activity level.

After adjusting for age, the risk of LTSA was significantly increased by smoking and BMI (Table 2, Model 2). Being a current smoker was associated with an increased risk of LTSA of 34\% (95\% CI: 1.17-1.54) compared to nonsmokers (the reference group). Being a former smoker was not associated with a higher risk of LTSA (HR: 1.05; 95\% CI: 0.89-1.23). In all four models, the association with leisure-time physical activity could be reduced to a general trend (all p-values $>0.5756$ ) and a higher physical activity was associated with a lower risk of LTSA (all trend test p-values $<0.0140$; results not shown). In other words, we found a dose-response relationship between leisuretime physical activity and LTSA, in that sedentary physical activity increased the risk of LTSA, while high physical activity protected against LTSA.

Regarding BMI, we found that the risk of LTSA was higher the further away BMI was from $18.5 \mathrm{~kg} / \mathrm{m}^{2}$ (in either direction). For individuals with a BMI below $18.5 \mathrm{~kg} / \mathrm{m}^{2}$ the risk of LTSA increased by $32 \%$ per $1 \mathrm{~kg} / \mathrm{m}^{2}$. For individuals with a BMI above $18.5 \mathrm{~kg} / \mathrm{m}^{2}$ the risk of LTSA increased by $4 \%$ per $1 \mathrm{~kg} / \mathrm{m}^{2}$. In other words, the more underweight or overweight a person is the higher the risk of LTSA. Additional calculations indicate that two people with BMI of, respectively, $16.5 \mathrm{~kg} / \mathrm{m}^{2}$ and $32 \mathrm{~kg} / \mathrm{m}^{2}$ have the same increased risk of LTSA; a relative risk of 1.74 compared to women with a BMI of $18.5 \mathrm{~kg} / \mathrm{m}^{2}$ and the same status on other risk factors (results not shown). We adjusted for a range of confounders (age, tenure, occupational type, physical workload, four measures of psychosocial work environment, and previous long-term sickness absence), but this adjustment did not alter the significant associations between the lifestyle risk-factors and LTSA, nor did it change the estimates in any sizeable way (Table 2, Model 3 and 4).

\section{Discussion \\ Summary of findings}

This study investigated the association between lifestyle and LTSA among female health care workers in Denmark. LTSA was significantly associated with all three healthrelated behaviours (smoking, physical activity and BMI). In line with previous studies $[13,15,18,20,40,41]$, we found that an unhealthy lifestyle, defined in terms of smoking, being physically inactive and having a high BMI, increased the risk of LTSA. In addition, we found that people with a BMI below $18.5 \mathrm{~kg} / \mathrm{m}^{2}$ have increased risk of LTSA with a higher risk for lower scores. This area is somewhat unstudied and 
Table 2 Hazard Ratios and confidence intervals for onset of long-term sickness absence during 12-months of follow-up

\begin{tabular}{|c|c|c|c|c|c|c|c|c|c|}
\hline \multirow[b]{2}{*}{ Variable } & \multirow[t]{2}{*}{$\mathrm{N}$} & \multicolumn{2}{|c|}{ Model 1} & \multicolumn{2}{|c|}{ Model 2} & \multicolumn{2}{|c|}{ Model 3} & \multicolumn{2}{|c|}{ Model 4} \\
\hline & & HR $(95 \% \mathrm{Cl})$ & P-value* & HR $(95 \% \mathrm{Cl})$ & P-value* & HR $(95 \% \mathrm{Cl})$ & P-value* & HR $(95 \% \mathrm{Cl})$ & P-value* \\
\hline Leisure-time physical activity & & & 0.0086 & & 0.0844 & & 0.0420 & & 0.0602 \\
\hline Sedentary & 305 & $1.34(1.02-1.75)$ & & $1.28(0.97-1.68)$ & & $1.34(1.02-1.77)$ & & $1.35(1.02-1.78)$ & \\
\hline Light & 3028 & $1.13(1.00-1.28)$ & & $1.09(0.96-1.23)$ & & $1.09(0.96-1.24)$ & & $1.08(0.95-1.22)$ & \\
\hline Moderate & 3604 & $1.00-$ & & $1.00-$ & & $1.00-$ & & $1.00-$ & \\
\hline Vigorous & 341 & $0.77(0.56-1.06)$ & & $0.81(0.58-1.12)$ & & $0.79(0.56-1.10)$ & & $0.80(0.57-1.13)$ & \\
\hline Missings & 123 & & & & & & & & \\
\hline Smoking & & & $<.0001$ & & $<.0001$ & & 0.0045 & & 0.0066 \\
\hline Never smoker & 2817 & $1.00-$ & & $1.00-$ & & $1.00-$ & & $1.00-$ & \\
\hline Former smoker & 1778 & $1.09(0.93-1.27)$ & & $1.05(0.89-1.23)$ & & $1.01(0.86-1.19)$ & & $1.00(0.84-1.18)$ & \\
\hline Current smoker & 2724 & $1.33(1.17-1.52)$ & & $1.35(1.17-1.54)$ & & $1.24(1.08-1.44)$ & & $1.23(1.06-1.42)$ & \\
\hline Missings & 82 & & & & & & & & \\
\hline BMI & & & $<.0001$ & & $<.0001$ & & $<.0001$ & & $<.0001$ \\
\hline 1 point lower BMI below 18.5 & 140 & $1.35(1.08-1.69)$ & & $1.32(1.06-1.66)$ & & $1.31(1.04-1.66)$ & & $1.33(1.05-1.69)$ & \\
\hline 1 point higher $\mathrm{BMI}$ above 18.5 & 6926 & $1.04(1.03-1.05)$ & & $1.04(1.03-1.06)$ & & $1.04(1.02-1.05)$ & & $1.03(1.02-1.05)$ & \\
\hline Missings & 335 & & & & & & & & \\
\hline LTSA & & & & & & & & & $<.0001$ \\
\hline PreviousLTSA & 7401 & . & . & . & . & . & & $2.02(1.75-2.33)$ & \\
\hline
\end{tabular}

Model 1: separate analyses, adjusted for age.

Model 2: combined lifestyle factors, adjusted for age.

Model 3: combined lifestyle factors, adjusted for age, tenure, physical and psychosocial work factors, occupational type.

Model 4: combined lifestyle factors, adjusted for age, tenure, physical and psychosocial work factors, occupational type and previous long-term sickness absence.

*P-values concern an overall test for the variable in question.

Significant results are presented in boldface.

results have previously been inconsistent. Neovius and collegues [40] found that underweight individuals had increased risk for short episodes of sickness absence, but decreased risk of long-term episodes, while Parkes [42] found a J-shaped relationship between BMI and sick-leave frequency, showing that underweight, overweight and obese individuals had increased risk of sick-leave compared to normal weight individuals. Our findings add to this rather overlooked area. In fact our results indicate that for women, being underweight is equally dangerous as being obese with regards to LTSA. However, in a society that puts such pressure on women for being skinny, the detrimental effects of being underweight are often neglected and ignored.

Smoking compared to non-smoking showed increased risk of LTSA of $35 \%$. This is in line with previous findings $[13-15,43,44]$. However, former smokers were not at increased risk of LTSA in our study, which contradicts findings from previous research $[8,15,43]$. With regards to leisure-time physical activity, we found a significant association with LTSA, supporting the notion that an inactive lifestyle increases the risk of LTSA. We found a dose-response pattern where vigorous physical activity seems to have a protective effect on LTSA. Other studies have also reported that vigorous physical activity during leisure-time is associated with reduced sickness absence [16-18,45]. Holtermann and colleagues investigated the effects of both occupational and leisure-time physical activity on LTSA in the general Danish population [46]. They also found that leisure-time physical activity decreased the risk of LTSA; however, occupational physical activity increased the risk of LTSA, indicating opposing effects of occupational and leisure-time physical activity [46].

The association between LTSA and lifestyle cannot be explained by confounding from the measured covariates; even with adjustment for working conditions, previous sickness absence and occupational type, all three lifestyle factors were strongly associated with LTSA. In other words, lifestyle factors are independent risk factors that influence sickness absence regardless of work environment.

\section{Strength and limitations}

A potential advantage of our study is the robust study design. We relied on register data, which we linked to the survey data, giving us valid measures on sickness absence. In other words, we did not have to rely on self-reported sickness data which are prone to recall bias. Furthermore, the DREAM register covers every person who has received social transfer payment, which eliminates dropout. Another strength of our study is that we investigated long-term 
sickness absence rather than short-term sickness absence. Causes of long- and short-term sickness absence can be very different; short spells of sickness absence can potentially reflect other factors than actual sickness (such as lack of motivation, truanting, pregnancy or the burden of family obligations $[47,48])$, while long-term sickness absence mostly requires medical confirmation from a doctor and is a predictor of expulsion from the labour marked in itself [12]. Investigating the associations among healthcare workers only is a strength of this study as it allows us to say something concrete about this particular occupational groups. However, the associations seen in this study cannot be generalized to e.g. men, other occupational sectors or other countries. Further studies are needed to evaluate the association between LTSA and lifestyle in other working populations. Restricting our population to a homogenous occupational group limited the social gradient as a source of confounding to a large extent. Thus, the study shows that the association between LTSA and lifestyle factors goes beyond simple confounding by social class. A limitation of our study was the use of self-reported data on all lifestyle variables; the use of self-reported data can cause bias as e.g. self-reported height and weight are often over-and underestimated, respectively $[49,50]$. The study relied on data originating from 2005 and results may not be directly transferable to today because of changes in sickness absence benefits. However, the changes have only affected the rules for payment/reimbursement of sickness benefits to the employer. Since LTSA is largely reflecting chronic disease [51] it is probably less affected by changes in benefits than short time sickness absence. For these reasons, we assess that the association between lifestyle and LTSA is robust to changes in sickness benefits. Finally, it should be noted that only 140 participants had a BMI below $18.5 \mathrm{~kg} / \mathrm{m}^{2}$, which could be relatively close to some floor value of BMI needed for survival (flooring effect). Thus, this could potentially explain the stronger effect per $\mathrm{kg} / \mathrm{m}^{2}$ among the underweight individuals.

\section{Implications}

The identified associations between lifestyle and LTSA suggest some workplace benefits of promoting healthy lifestyles. The cost of sickness absence (due to lost productivity, health-care costs etc.) may serve as a motivation for companies to provide employees with health-promoting initiatives, such as exercise rooms, changes in the available food and beverages, or offering weight loss- and smoking cessation programs. Thus, improving employee health through worksite changes and initiatives can potentially lead to a reduction in sickness absence. Smoking bans, food- and alcohol regulations, creating visible stairways and adding exercise rooms are worksite structural changes that can endorse a healthier choice. In a comprehensive review,
Mozaffarian and colleagues systematically reviewed evidence-based population-based strategies that has been proven efficient in helping lifestyle changes [52]. They found that certain workplace interventions and programmes, such as changes in available food and beverages, nutritional education, stress management, and smoking restrictions did improved dietary habits and reduced the use of tobacco [52]. However, many of the recent reviews, including the before-mentioned, indicate the need for more well-designed studies, in particularly with regards to physical activity as the effectiveness of these are limited and inconclusive [52,53]. Similarly, a recent meta-analysis on the effectiveness of workplace health promotion programs by Rongen et al. [54] concluded that the overall effect was small. Rongen and colleagues [54] found that it was not only the intervention itself, but also the underlying components such as the study population, study characteristics and quality of the methodology, that were key components for the effectiveness. Workplace health promotion programs were more effective among younger populations, when interventions included weekly contacts and when the control group received no health promotion [54].

\section{Conclusion}

This study adds knowledge about the association between lifestyle and sickness absence, and addresses the somewhat overlooked relationship between underweight and sickness absence. We found that unhealthy behaviours (smoking, extreme BMI, and low physical activity) are predictive of LTSA among female health care workers. Further, it points to the potential of reducing long-term sickness absence if improvements are made regarding personal health behaviours, such as quitting smoking, increased physical activity and obtaining/maintaining a BMI in the normal range. In order to reduce sickness absence, which would provide important societal and personal gains, the society, community and worksites must, in collaboration with each other, encourage, support and plan for health-promoting programmes aimed at improving healthy lifestyles in addition to ensuring a safe work environment.

\section{Abbreviations}

LTSA: Long-term sickness absence; BMI: Body mass index; DREAM: Danish register for evaluation of marginalization; COPSOQ: Copenhagen

psychosocial questionnaire; HR: Hazard ratios; Cl: Confidence interval.

\section{Competing interests}

The authors declare that they have no competing interests.

\section{Authors' contributions}

LLA developed the idea for the article, developed the design and has overseen the entire process. LLA also provided critical feedback with regards to interpretations of the results. HGQ was responsible for the data processing, statistical analyses, interpretation of the results and the writing of the manuscript. Furthermore, HGQ has prepared it for publication. BLT has significantly contributed to the statistical analyses, interpretation of the results and the design of the study. UC and JBJ have provided critical 
feedback regarding the study design and interpretation of the results. JBJ, $\mathrm{AHO}$ and TCL have provided critical revisions to the manuscript. All authors have read and approved the manuscript in its final form.

\section{Acknowledgements}

The cohort study was financed by the Danish Government through a three-year grant to the FOR-SOSU program at the National Research Centre for the Working Environment. The completion of this manuscript was funded by a grant from The Danish Working Environment Research Fund. Neither of the funding sources took part in the study design, data collection and analyses, writing of the manuscript, or decisions regarding publication.

\section{Author details}

${ }^{1}$ National Research Centre for the Working Environment, Lerso Parkallé 105 2100 Copenhagen, Denmark. ${ }^{2}$ Department of Public Health, University of Copenhagen, Section of Social Medicine, Oster Farimagsgade 5, 1014 Copenhagen, Denmark. ${ }^{3}$ QualityMetric/Optumlnsight, 24 Albion Road, 02865 Lincoln, RI, USA.

Received: 19 April 2014 Accepted: 13 October 2014 Published: 18 October 2014

\section{References}

1. Andersen LL, Clausen T, Mortensen OS, Burr H, Holtermann A: A prospective cohort study on musculoskeletal risk factors for long-term sickness absence among healthcare workers in eldercare. Int Arch Occ Env Hea 2012, 85(6):615-622.

2. Danish Ministry of Employment: Nye Sygedagpengeregler fra 1. Juli 2014 (New Rules on Sickness Absence from July 1st, 2014). København: Danish Ministry of Employment; 2014. 28-9-201.

3. Benavides FG: III health, social protection, labour relations, and sickness absence. Occup Environ Med 2006, 63(4):228-229.

4. Albertsen K, Lund T, Christensen KB, Kristensen TS, Villadsen E: Predictors of disability pension over a 10-year period for men and women. Scand J Public Health 2007, 35(1):78-85.

5. Andersen L, Clausen T, Persson R, Holtermann A: Dose-response relation between perceived physical exertion during healthcare work and risk of long-term sickness absence. Scand J Work Environ Health 2012, 38(6):582-589.

6. Christensen KB, Lund T, Labriola M, Villadsen E, Bultmann U: The fraction of long-term sickness absence attributable to work environmental factors: prospective results from the Danish Work Environment Cohort Study. Occup Environ Med 2007, 64(7):487-489.

7. Lund T, Labriola M, Christensen KB, Bultmann U, Villadsen E: Physical work environment risk factors for long term sickness absence: prospective findings among a cohort of 5357 employees in Denmark. BMJ 2006 332(7539):449-451.

8. Christensen KB, Lund T, Labriola M, Bultmann U, Villadsen E: The impact of health behaviour on long term sickness absence: results from DWECS/DREAM. Ind Health 2007, 45(2):348-351.

9. Lund T, Labriola M, Christensen KB, Bultmann U, Villadsen E, Burr H: Psychosocial work environment exposures as risk factors for long-term sickness absence among Danish employees: Results from DWECS/DREAM. J Occup Environ Med 2005, 47(11):1141-1147.

10. Lund T, Iversen L, Poulsen KB: Work environment factors, health, lifestyle and marital status as predictors of job change and early retirement in physically heavy occupations. Am J Ind Med 2001, 40(2):161-169.

11. Marmot M, Feeney A, Shipley M, North F, Syme SL: Sickness absence as a measure of health-status and functioning: from the UK Whitehall II study. J Epidemiol Community Health 1995, 49(2):124-130.

12. Lund T, Kivimaki M, Labriola M, Villadsen E, Christensen KB: Using administrative sickness absence data as a marker of future disability pension: the prospective DREAM study of Danish private sector employees. Occup Environ Med 2008, 65(1):28-31.

13. Alavinia SM, van den Berg TIJ, van Duivenbooden C, Elders LAM, Burdorf A Impact of work-related factors, lifestyle, and work ability on sickness absence among Dutch construction workers. Scand J Work Environ Health 2009, 35(5):325-333.

14. Laaksonen M, Piha K, Martikainen P, Rahkonen O, Lahelma E: Health-related behaviours and sickness absence from work. Occup Environ Med 2009, 66:840-847.
15. Labriola M, Lund T, Burr $\mathrm{H}$ : Prospective study of physical and psychosocial risk factors for sickness absence. Occup Med 2006, 56(7):469-474.

16. Lahti J, Laaksonen M, Lahelma E, Rahkonen O: The impact of physical activity on sickness absence. Scand J Med Sci Sports 2010, 20(2):191-199.

17. Lahti J, Lahelma E, Rahkonen O: Changes in leisure-time physical activity and subsequent sickness absence: A prospective cohort study among middle-aged employees. Prev Med 2012, 55:618-622

18. van Amelsvoort LGPM, Spigt MG, Swaen GMH, Kant I: Leisure time physical activity and sickness absenteeism; a prospective study. Occup Med 2006, 56(3):210-212

19. Bigaard J, Frederiksen K, Tjonneland A, Thomsen BL, Overvad K, Heitmann $\mathrm{BL}$, Sorensen TIA: Waist circumference and body composition in relation to all-cause mortality in middle-aged men and women. Int J Obesity 2005, 29(7):778-784

20. Neovius K, Johansson K, Kark M, Neovius M: Obesity status and sick leave: a systematic review. Obs Rev 2009, 10(1):17-27.

21. Lynch JW, Kaplan GA, Salonen JT: Why do poor people behave poorly? Variation in adult health behaviours and psychosocial characteristics by stages of the socioeconomic lifecourse. Soc Sci Med 1997, 44(6):809-819.

22. Hammer-Helmich L, Buhelt L, Andreasen A, Robinson K, Hilding-Nørkjær $H_{\text {, }}$ Glümer C: Sundhedsprofil for Region og Kommuner 2010. Glostrup, Region Hovedstaden: Forskningscenter for Forebyggelse og Sundhed; 2010.

23. Christensen KB, Labriola M, Lund T, Kivimaki M: Explaining the social gradient in long-term sickness absence: a prospective study of Danish employees. J Epidemiol Community Health 2008, 62(2):181-183.

24. Clausen T, Nielsen K, Carneiro IG, Borg V: Job demands, job resources and long-term sickness absence in the Danish eldercare services: a prospective analysis of register-based outcomes. J Adv Nurs 2012, 68(1):127-136.

25. Laaksonen M, Mastekaasa A, Martikainen P, Rahkonen O, Piha K, Lahelma E: Gender differences in sickness absence - the contribution of occupation and workplace. Scand J Work Environ Health 2010, 36(5):394-403.

26. Labriola M, Holte KA, Christensen KB, Feveile $H$, Alexanderson $K$, Lund T: The attribution of work environment in explaining gender differences in long-term sickness absence: results from the prospective DREAM study. Occup Environ Med 2011, 68(9):703-705.

27. Foss L, Gravseth HM, Kristensen P, Claussen B, Mehlum IS, Knardahl S, Skyberg K: The impact of workplace risk factors on long-term musculoskeletal sickness absence a registry-based 5-year follow-Up from the Oslo health study. J Occup Environ Med 2011, 53(12):1478-1482.

28. Arbejdsmarkedsstyrelsen: Beskrivelse af DREAM-Koder - Version 28 (Report in Danish: Description of DREAM Entries - Version 28). Arbejdsmarkedsstyrelsen (Danish National Labour Market Authority); 2012

29. Borg V, Clausen T, Frandsen C, Winsløv J: Psykisk Arbejdsmiljø i Aldreplejen - Bilag til Rapport nr. 4 (Psychological Work Environment in the Eldercare - Appendix to Report no. 4). Copenhagen, Denmark: Danish National Research Centre for the Working Environment. Report No:: 4; 2005

30. Hjollund NH, Larsen FB, Andersen $\mathrm{JH}$ : Register-based follow-up of socia benefits and other transfer payments: Accuracy and degree of completeness in a Danish interdepartmental administrative database compared with a population-based survey. Scand J Public Health 2007, 35(5):497-502.

31. Stapelfeldt CM, Jensen C, Andersen NT, Fleten N, Nielsen CV: Validation of sick leave measures: self-reported sick leave and sickness benefit data from a Danish national register compared to multiple workplace-registered sick leave spells in a Danish municipality. BMC Public Health 2012, 12:661-671.

32. Saltin B, Grimby G: Physiological analysis of middle-aged and Old former athletes - comparison with still active athletes of same ages. Circulation 1968, 38(6):1104

33. Hollmann S, Klimmer F, Schmidt KH, Kylian H: Validation of a questionnaire for assessing physical work load. Scand J Work Environ Health 1999, 25(2):105-114

34. Kristensen TS, Hannerz H, Hogh A, Borg V: The Copenhagen psychosocial questionnaire - a tool for the assessment and improvement of the psychosocial work environment. Scand J Work Environ Health 2005, 31(6):438-449.

35. Pejtersen JH, Kristensen TS, Borg V, Bjorner JB: The second version of the Copenhagen psychosocial questionnaire. Scand J Public Health 2010, 38:8-24.

36. Quist HG, Christensen U, Christensen KB, Aust B, Borg V, Bjorner JB: Psychosocial work environment factors and weight change: a prospective study among Danish health care workers. BMC Public Health 2013, 13:43-51.

37. Allard KO, Thomsen JF, Mikkelsen S, Rugulies R, Mors O, Kærgaard A, Kolstad HA, Kaelev L, Andersen JH, Hansen ÅM, Bonde JPE: Effects of 
psychosocial work factors on lifestyle changes. J Occup Environ Med 2011, 53(12):1364-1371.

38. Prentice RL, Gloeckler LA: Regression-analysis of grouped survival data with application to breast-cancer data. Biometrics 1978, 34(1):57-67.

39. Greenland S: Dose-response and trend analysis in epidemiology - alternatives to categorical analysis. Epidemiology 1995, 6(4):356-365.

40. Neovius K, Neovius M, Kark M, Rasmussen F: Association between obesity status and sick-leave in Swedish men: nationwide cohort study. Eur J Public Health 2012, 22(1):112-116.

41. van Duijvenbode DC, Hoozemans MJM, van Poppel MNM, Proper KI: The relationship between overweight and obesity, and sick leave: a systematic review. Int J Obesity 2009, 33(8):807-816.

42. Parkes KR: Relative weight, smoking, and mental-health as predictors of sickness and absence from work. J Appl Psychol 1987, 72(2):275-286.

43. Weng S, Ali S, Leonardi-Bee J: Smoking and absence from work: systematic review and meta-analysis of occupational studies. Addiction 2012, 108:307-319.

44. Christensen KB, Feveile H, Labriola M, Lund T: The impact of psychosocial work environment factors on the risk of disability pension in Denmark. Eur J Public Health 2008, 18(3):235-237.

45. van den Heuvel SG, Boshuizen HC, Hildebrandt VH, Blatter BM, Ariens GA, Bongers PM: Effect of sporting activity on absenteeism in a working population. Brit J Sport Med 2005, 39:e5.

46. Holtermann A, Hansen JV, Burr H, Sogaard K, Sjogaard G: The health paradox of occupational and leisure-time physical activity. Brit J Sport Med 2012, 46(4):291-295.

47. Mastekaasa A: Parenthood, gender and sickness absence. Soc Sci Med 2000, 50(12):1827-1842.

48. Alexanderson K, Sydsjo A, Hensing G, Sydsjo G, Carstensen J: Impact of pregnancy on gender differences in sickness absence. Scand I Soc Med 1996, 24(3):169-176.

49. Gorber SC, Tremblay M, Moher D, Gorber B: A comparison of direct vs. self-report measures for assessing height, weight and body mass index: a systematic review. Obs Rev 2007, 8(4):307-326.

50. Krul AJ, Daanen HAM, Choi H: Self-reported and measured weight, height and body mass index (BMI) in Italy, the Netherlands and North America. Eur J Public Health 2011, 21(4):414-419.

51. Henderson M, Glozier N, Elliott KH: Long term sickness absence - Is caused by common conditions and needs managing. BMJ 2005, 330(7495):802-803.

52. Mozaffarian D, Afshin A, Benowitz NL, Bittner V, Daniels SR, Franch HA, Jacobs DR, Kraus WE, Kris-Etherton PM, Krummel DA, Popkin BM, Whitsel LP, Zakai NA: Population approaches to improve diet, physical activity, and smoking habits a scientific statement from the American Heart Association. Circulation 2012, 126(12):1514.

53. Malik S, Blake H, Suggs S: A systematic review of workplace health promotion interventions for increasing physical activity. Brit J Health Psych 2014, 19:149-180.

54. Rongen A, Robroek SJW, van Lenthe FJ, Burdorf A: Workplace health promotion a meta-analysis of effectiveness. Am J Prev Med 2013, 44(4):406-415.

doi:10.1186/1471-2458-14-1084

Cite this article as: Quist et al: Influence of lifestyle factors on long-term sickness absence among female healthcare workers: a prospective cohort study. BMC Public Health 2014 14:1084.

\section{Submit your next manuscript to BioMed Central and take full advantage of:}

- Convenient online submission

- Thorough peer review

- No space constraints or color figure charges

- Immediate publication on acceptance

- Inclusion in PubMed, CAS, Scopus and Google Scholar

- Research which is freely available for redistribution

Submit your manuscript at www.biomedcentral.com/submit 